\title{
Clinicopathological and Survival Pattern in Lung Cancer Patients of Different Age Group
}

\author{
Yumkhaibam Sobita Devi, Srigopal Mohanty ${ }^{*}$, Laishram Jaichand Singh, \\ Daffilyne Lyngdoh Nongrum
}

Department of Radiotherapy, Regional Cancer Centre, Regional Institute of medical Science, Imphal, India

Email address:

drsrigopal17@gmail.com (S. Mohanty)

${ }^{*}$ Corresponding author

\section{To cite this article:}

Yumkhaibam Sobita Devi, Srigopal Mohanty, Laishram Jaichand Singh, Daffilyne Lyngdoh Nongrum. Clinicopathological and Survival Pattern in Lung Cancer Patients of Different Age Group. International Journal of Clinical Oncology and Cancer Research.

Vol. 3, No. 3, 2018, pp. 25-29. doi: 10.11648/j.ijcocr.20180303.12

Received: June 12, 2018; Accepted: July 1, 2018; Published: July 26, 2018

\begin{abstract}
Lung cancer is considered as disease of older population with median age of 70 year at diagnosis. The aim of this study was to investigate the clinicopathological and survival pattern in younger and older age lung cancer patients. A retrospective study was carried out for all histopathologically or cytologically confirmed cases of primary lung cancer treated between 2011 and 2015at the Regional Cancer Centre, Imphal, Manipur, India. Cases were grouped into two age groups, i.e. the younger age group ( $<60$ year) and the older age group ( $\geq 60$ year). Out of the total 432 cases of primary lung cancer, 124 were diagnosed at $<60$ year of age with median age of 55 year and 308 patients were diagnosed at $\geq 60$ year of age with median age of 70 year at diagnosis. Younger age group was found to have significantly lesser number of chronic smokers $(p=0.000)$, lesser history of pulmonary tuberculosis $(\mathrm{p}=0.019)$, higher rate of adenocarcinoma $(\mathrm{p}=0.000)$, more positive family history $(\mathrm{p}=0.008)$, more advanced stage (III \& IV) at presentation $(\mathrm{p}=0.000)$, greater proportion of patients undergone combined modality of treatment and lesser proportions of patients refused active cancer treatment $(\mathrm{p}=0.002)$ as compared to older age group. Response to treatment in terms of median survival $(\mathrm{p}=0.338)$ and three year overall survival $(\mathrm{p}=0.344)$ was found similar in both the age groups in spite of more advanced stage of the disease at presentation in younger age group, the reasons could be lesser proportion of older age patients got combined modality treatment due to greater comorbidities, poor performance status \& greater proportion of older age patients refused active cancer treatment, because of lesser expectation in terms of long term benefit with treatment.
\end{abstract}

Keywords: Age Variation, Clinicopathology, Lung Cancer, Survival

\section{Introduction}

Lung cancer is the most common cause of cancer-related death in the United States and worldwide [1, 2]. Despite recent advances in treatment, prognosis of patients with lung cancer remains poor, with 5-year overall survival of approximately $15 \%$. Lung cancer is often considered a disease of the older population with a median age at diagnosis of about 70 year [3]. Some studies have suggested that younger patients with lung cancer have a more aggressive disease course and a worse prognosis than older patients [4-7], other investigators have reported that the survival of lung cancer in younger and older patient cohorts is similar [8-11], whereas some other studies have shown improved survival in younger patients [12-17]. The present study is aimed to identify and evaluate the known clinicopathological factors and to elucidate the clinical significance of patient age on the outcome of lung cancer.

\section{Material and Methods}

The retrospective study was carried out obtaining data from registry of Regional Cancer Centre, Regional Institute of Medical Science, Imphal, Manipur. Study population included all histopathologically or cytologically confirmed cases of primary lung cancer registered and treated between 2011 to 2015. IBM SPSS-21 version for windows was used for all data analysis. Variables like age, sex, smoking habit, family history, history of Pulmonary tuberculosis/Asthma/COPD, histopathologic subtype, stage were analyzed using Chi square analysis (two sided). $\mathrm{P}$ value $<0.05$ was considered as 
significant difference. Survival was analyzed using Kaplan Meier survival analysis and compared by log rank testing.

\section{Results}

\subsection{Demographic Characteristics}

Out of the total 432 lung cancer patients, 124 (28.7\%) were $<60$ years and $308(71.3 \%)$ were $\geq 60$ years at diagnosis. Within the younger age group, $102(82.3 \%)$ were between 50 to 59 years, $17(13.7 \%)$ were between 40 to 49 years, and only $5(4.0 \%)$ were between 30 to 39 years of age. The median ages of the younger and older age groups were 55 and 70 years, respectively (Table 1). The differences in distribution of disease with gender between the two age groups were not found statistically significant $(p=0.451)$ (Table 1). History of chronic smoking was found in 61
(49.2\%) patients of younger age group and $250(81.2 \%)$ patients of the older age group, which shows a statistically significant $(p=0.00)$ decreasing trend of smoking habit in younger age group (Table 1). This decreasing trend of smoking habit in younger patients is an indicator of successful Anti tobacco awareness programme in North Eastern India. Positive history of co morbidities like asthma or COPD was found lesser in younger age group (1.6\%) compared to older age group (4.9\%), though the difference was not significant $(\mathrm{p}=0.115)$. Positive family history of lung cancer was found significantly higher $(p=0.008)$ among younger age group i.e. $4.8 \%$ as compared to $0.6 \%$ in older age group. Previous history of tuberculosis was found significantly lesser $(p=0.01)$ in younger age group $(7.3 \%)$ as compared to in older age group (17.5\%) (Table 1).

Table 1. Demographic Characteristic.

\begin{tabular}{llll}
\hline & Age $<\mathbf{6 0}$ (in years) $\mathbf{N}=\mathbf{1 2 4}$ & Age $\geq \mathbf{6 0}$ (in years) $\mathbf{N}=\mathbf{3 0 8}$ & P value \\
\hline Median age & 55 & 70 & \\
Male & $69(55.7 \%)$ & $184(59.7 \%)$ & 0.434 \\
Female & $55(44.3 \%)$ & $124(40.3 \%)$ & 0.000 \\
Smokers & $61(49.2 \%)$ & $250(81.2 \%)$ & 0.115 \\
Asthma \& COPD & $2(1.6 \%)$ & $15(4.9 \%)$ & 0.019 \\
H/o pulmonary Tuberculosis (TB) & $9(7.3 \%)$ & $54(17.5 \%)$ & 0.008 \\
Positive family history & $6(4.8 \%)$ & $2(0.6 \%)$ & \\
\hline
\end{tabular}

\subsection{Pathologic Characteristics}

The distribution of histopathologic subtypes in younger age group was found to differ significantly from that in older age group $(p=0.000)$. Younger age group have adenocarcinoma $(61.3 \%)$ as the most common type followed by squamous cell carcinoma $(29.8 \%)$, small cell carcinoma $(4.8 \%)$, others $(4.1 \%)$. Whereas most common subtype in older age group were squamous cell carcinoma (58.1\%) followed by adenocarcinoma (27.6\%), small cell carcinoma $(10.7 \%)$, others $(3.6 \%)$ (Table 2$)$. Stage distribution was significantly different between the age groups $(p=0.000)$,younger age group found to have more advanced stage at presentation with $94.4 \%$ younger patients presented in stage III or IV compared to $77.3 \%$ among older patients (Table 2).

Table 2. Pathological Characteristics.

\begin{tabular}{llll}
\hline Histopathology \& Stage & Age $<$ 60yearN=124 & Age $\geq \mathbf{6 0 y e a r N = 3 0 8}$ & p value \\
\hline Squamous & $37(29.9 \%)$ & $179(58.2 \%)$ & \\
Adeno & $76(61.3 \%)$ & $85(27.6 \%)$ & 0.000 \\
Small cell & $6(4.8 \%)$ & $33(10.7 \%)$ & \\
Others & $5(4 \%)$ & $11(3.5 \%)$ & \\
Stage I & $1(0.8 \%)$ & $2(0.6 \%)$ & 0.000 \\
Stage II & $6(4.8 \%)$ & $68(22 \%)$ & \\
Stage III & $57(46 \%)$ & $132(42.9 \%)$ & \\
Stage IV & $60(48.4 \%)$ & $106(34.5 \%)$ & \\
\hline
\end{tabular}

\subsection{Treatment Characteristics}

There was significant difference $(\mathrm{p}=0.002)$ in modalities of treatments received in each age group. Total 75 patients $(60.5 \%)$ in younger age group received combined modality treatment in the form of surgery, chemotherapy, radiotherapy as per standard protocol, compared to $134(43.5 \%)$ in older age group. Total $12(3.9 \%)$ patients in older age group refused treatment and majorities were of age $>80$ years, whereas all younger age group received treatment (Table 3 ).

Table 3. Treatment characteristics.

\begin{tabular}{lll}
\hline Treatment & Age $<\mathbf{6 0 y e a r N = 1 2 4}$ & Age $\geq \mathbf{6 0 y e a r} \mathbf{N}=\mathbf{3 0 8}$ \\
\hline CT & $46(37.1 \%)$ & $135(43.8 \%)$ \\
RT & $03(2.4 \%)$ & $27(8.8 \%)$ \\
CMT & $75(60.5 \%)$ & $134(43.5 \%)$ \\
No treatment & 0 & $12(3.9 \%)$ \\
\hline
\end{tabular}




\subsection{Survival Characteristics}

Median survival was 15 months among younger age group whereas 12 months among older age group $(\mathrm{p}=0.338)$. Three year overall survival was found to be $3.2 \%$ in younger age group as compared to $6.5 \%$ in older age group, survival difference was statistically not significant $(\mathrm{p}=0.344)$. The reason behind this may be more aggressiveness of cancer in younger age group, greater comorbidities among older age group, greater proportion in older age group refusing treatment (Table4).

Table 4. Survival Characteristics.

\begin{tabular}{llll}
\hline Survival & Age $<\mathbf{6 0}($ in years) $\mathbf{N}=\mathbf{1 2 4}$ & Age $\geq \mathbf{6 0}$ (in years) $\mathbf{N}=\mathbf{3 0 8}$ & P value \\
\hline Median Survival & 15 months & 12 Months & 0.338 \\
3year OS & $4(3.2 \%)$ & $20(6.5 \%)$ & 0.344 \\
\hline
\end{tabular}

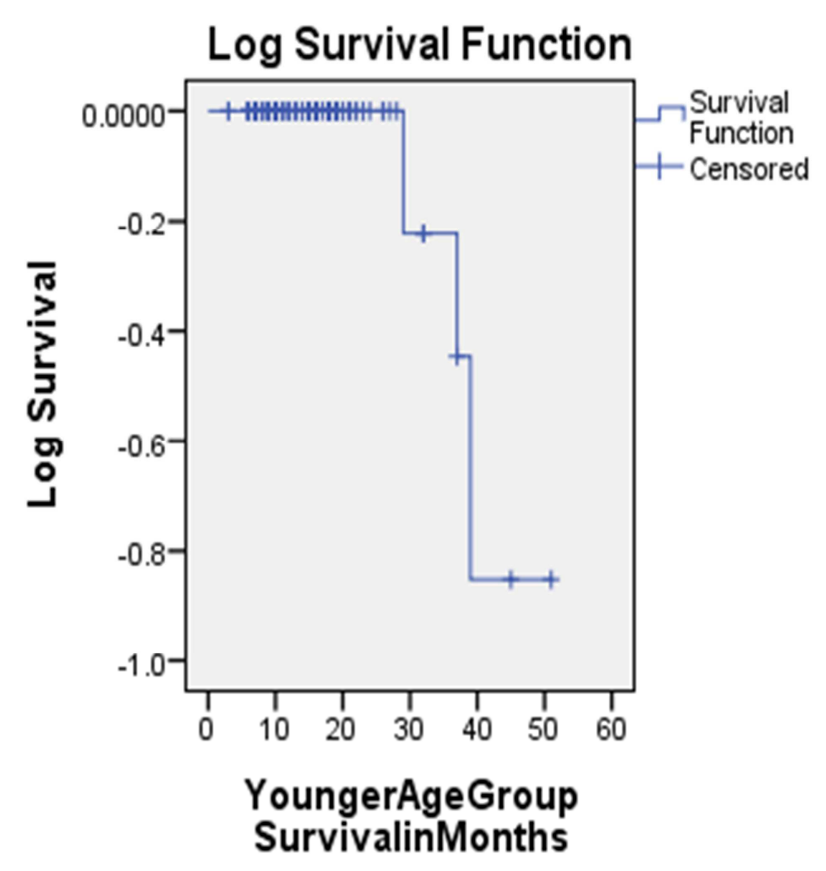

Figure 1. Log rank survival chart for younger age group.

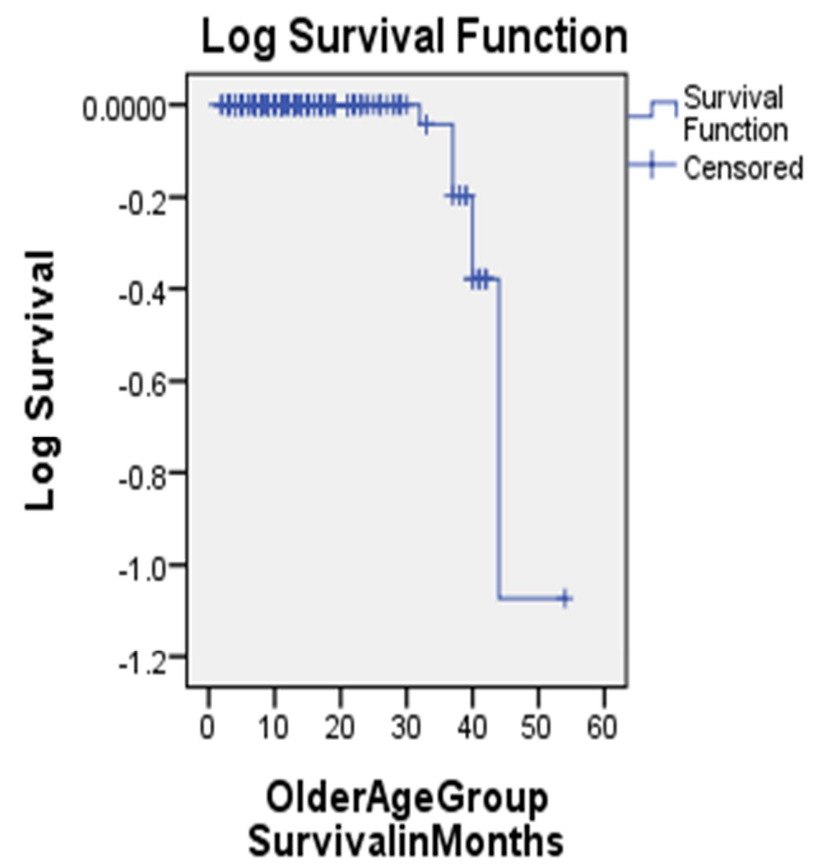

Figure 2. Log rank survival chartfor older age group.

\section{Discussion}

Due to increasing life expectancy and the increased risk of cancer with ageing, lung cancer is common in elderly individuals. More than half of lung cancer cases are diagnosed in patients aged $>65$ years [18-20]. The median age at diagnosis of lung cancer is between 64 and 70 years $[19,20]$.In the present study the median age was 66 years for all age groups, 55 year for younger age group and 70 year for older age group patients. The distribution by gender in the elderly is similar to that in younger patients in the US; whereas, in France, there is a decrease in the male/female ratio with increasing age $[21,22]$. In this study, the disease distribution by gender was found to be similar in both younger and older age group. Significantly lesser number of smokers with greater proportion of adenocarcinoma was found among younger age group as compared to older age group, which reflects the successful anti tobacco awareness programme in recent time. Significantly greater positive family history with more advanced stage disease at presentation was found in younger age group, which warrants further clinical studies with cytogenetic analysis to correlate genetic predisposition with early age at presentation and more aggressiveness of the cancer. Toxic events with chemotherapy are more common in elderly patients. Alterations of physiological functions, particularly renal and hematopoietic functions, with aging may explain increased chemotherapy toxicity in elderly patients [19, 23, 24]. Furthermore, elderly patients have more comorbidities than their younger counterparts and thus often take medications that may interfere with the chemotherapeutic drug metabolism. Comorbidities are responsible for an increased mortality in patients even after adjustment for age and stage $[19,25,26]$. In this study proportions of patients receiving combined modality treatment were significantly greater in younger age patients compared to older age patients. Proportions of patients did not go for any active treatment were significantly higher in older age group, probably because of multiple co morbidities, poor performance status and lesser expectation in terms of long term benefit with treatment. Studies performed on elderly patients with various malignancies show that elderly patients benefit from chemotherapy to a similar extent as younger patients, with manageable side effects [27-29].The vast majority of these subgroup analyses demonstrated that the efficacy results are 
similar in patients aged $<70$ years old and in those aged $\geq 70$ years old [28-32].In this study in spite of more advanced stage of presentation of disease in younger age patients and more co morbidities in older age patients, the overall survival was found similar in both the groups.

\section{Conclusion}

The decreasing number of smokers in younger age group signifies successful anti tobacco awareness programme in the North East part of India since last few decades. Greater incidence of adenocarcinoma, greater positive family history and greater aggressiveness of disease in younger age group needs further clinical studies with genetic analysis to correlate genetic predisposition with disease aggressiveness. Besides histopathology, stage of disease, appropriate treatment protocol, survival of lung cancer patients depend on age at diagnosis, comorbidities, patient's performance status.

\section{References}

[1] Goldstraw P, Crowley J, Chansky K, et al. The IASLC lung cancer staging project: proposals for the revision of the TNM stage groupings in the forthcoming (seventh) edition of the TNM classification of malignant tumours. J Thorac Oncol 2007; 2(8):706-14.

[2] Siegel R, Naishadham D, Jemal A. Cancer statistics 2012. CA Cancer J Clin 2012; 62(1):10-29.

[3] Howlader NNA, Krapcho M, et al. SEER Cancer Statistics Review, 1975-2010. Bethesda, MD: National Cancer Institute 2013. Available from: http://seer. cancer.gov/csr/1975_2010.

[4] Neuman HW, Ellis FH, McDonald JR. Bronchogenic carcinoma in persons under 40 years of age. N Engl $\mathrm{J}$ Med 1956;254:502-507.

[5] Bourke W, Milstein D, Giura R et al. Lung cancer in young adults. Chest 1992;102:1723-1729.

[6] Antkowiak JG, Regal A, Hiroshi T. Bronchogenic carcinoma in patients under age 40. Ann ThoracSurg 1989;47:391-393.

[7] DeCaro L, Benfield JR. Lung cancer in young persons. J Thorac Cardiovasc Surg 1982;83:372-376.

[8] Gadgeel SM, Ramalingam S, Cummings G, et al. Lung cancer in patients $<50$ years of age: the experience of an academic multidisciplinary program. Chest 1999;115:1232-1236.

[9] Maruyama R, Yoshino I, Yohena T, et al. Lung cancer in patients younger than 40 years of age. J Surg Oncol 2001;77:208-212.

[10] Mauri D, Pentheroudakis G, Bafaloukos D, et al. Non small cell lung cancer in the young: a retrospective analysis of diagnosis, management and outcome data. Anticancer Res 2006;26:3175-3181.

[11] Skarin AT, Herbst RS, Leong TL, et al. Lung cancer in patients under age 40. Lung Cancer 2001;32:255-264.

[12] Lara MS, Brunson A, Wun T, et al. Predictors of survival for younger patients less than 50 years of age with non small cell lung cancer (NSCLC): a California Cancer Registry analysis. Lung Cancer 2014;85:264-269.

[13] Nugent MD, Edney MT, Hammerness PG, et al. Non-small cell lung cancer at the extremes of age: impact on diagnosis and treatment. Ann ThoracSurg 1997;63:193-197.

[14] Subramanian J, Morgensztern D, Goodgame B, et al. Distinctive characteristics of non-small cell lung cancer (NSCLC) in the young: a Surveillance, Epidemiology, and End Results (SEER) analysis. J Thorac Oncol 2010;5:23-28.

[15] Thomas A, Chen Y, Yu T, et al. Trends and characteristics of young non-small cell lung cancer patients in the United States. Front Oncol 2015;5:113

[16] Kuo C-W, Chen Y-M, Chao J-Y, et al. Non-small cell lung cancer in very young and very old patients. Chest 2000;117:354-357.

[17] Arnold BN, Thomas DC, Rosen JE, et al. Lung cancer in the very young: treatment and survival in the national cancer data base. J Thorac Oncol 2016;7:1121-1131.

[18] Makrantonakis PD, Galani E, Harper PG.Non-small cell lung cancer in the elderly. Oncologist 2004;9:556-560.

[19] Maione P, Rossi A, Sacco PC et al. Treating advanced nonsmall cell lung cancer in the elderly. Ther Adv Med Oncol 2010;2;251-260.

[20] Owonikoko TK, Ragin CC, Belani CP et al. Lung cancer in elderly patients: an analysis of the surveillance, epidemiology and end results database. J Clin Oncol 2007; 25:5570-5577.

[21] Blanchon F, Grivaux M, Zureik M et al. Cohort KBP-2000CPHG: Evaluation of factors influencing survival in lung cancer. Rev Mal Respir (In French) 2006; 23:165-171.

[22] Quoix E and Lemarie E. Epidemiological novelties in lung cancer. Rev Mal Respir(In French)2011;28:1048-1058.

[23] Balducci L, Hardy CL and Lyman GH. Hemopoietic reserve in the older cancer patient, clinical and economic considerations. Cancer Control 2000; 7:539-547.

[24] Balducci L. Geriatric oncology, challenge for the new century. Eur J Cancer 2000; 36: 1741-1754.

[25] Kelly K, Crowley J, Bunn PA Jr et al. Randomized phase III trial of paclitaxel plus carboplatin versus vinorelbine plus cisplatin in the treatment of patients with advanced non-smallcell lung cancer: a Southwest Oncology Group trial. J Clin Oncol 2001; 19:3210-3218.

[26] Repetto L, Venturino A, Vercelli M et al. Performance status and comorbidity in elderly cancer patients compared with young patients with neoplasia and elderly patients without neoplastic conditions. Cancer 1998; 82:760-765.

[27] Earle CC, Tsai JS, Gelber RD, Weinstein MC, Neumann PJ and Weeks JC. Effectiveness of chemotherapy for advanced lung cancer in the elderly: instrumental variable and propensity analysis. J Clin Oncol 2001; 19:1064-1070.

[28] Langer CJ, Manola J, Bernardo P, et al. Cisplatin-based therapy for elderly patients with advanced non-small-cell lung cancer: implications of Eastern Cooperative Oncology Group 5592, a randomized trial. J Natl Cancer Inst 2002:94, 173-181. 
[29] Langer CJ, Vangel M and Schiller J).Age-specific sub analysis of ECOG 1594, fit elderly patients (70-80 yrs) with NSCLC do as well as younger pts $(<70)$. Proc Am Soc Clin Oncol $2003 ; 22: 639$.

[30] Lilenbaum RC, Herndon JE II, List MA, et al. Single-agent versus combination chemotherapy in advanced non small cell lung cancer: the cancer and leukemia group B (study 9730). J Clin Oncol 2005;23:190-196.

[31] Belani CP and Fossella FV. Phase III study (TAX 326) of docetaxel-cisplatin and docetaxel-carboplatin versus vinorelbine-cisplatin for the first-line treatment of advanced/metastatic non-small cell lung cancer: analyses in elderly patients. Lung Cancer 2003; 41(Suppl 2):S18.

[32] Ansari RH, Socinski MA, Edelman MJ et al. A retrospective analysis of outcomes by age in a three-arm phase III trial of gemcitabine in combination with carboplatin or paclitaxel vs. paclitaxel plus carboplatin for advanced non-small cell lung cancer. Crit Rev Oncol Hematol 2011; 78:162-171. 